\title{
In Situ Chemical Aminoacylation with Amino Acid Thioesters \\ Linked to a Peptide Nucleic Acid
}

\author{
Keiko Ninomiya, Toshikazu Minohata, Masaki Nishimura \\ and Masahiko Sisido* \\ Department of Bioscience and Biotechnology, \\ Faculty of Engineering, Okayama University \\ 3-1-1 Tsushimanaka, Okayama 700-8530, Japan
}

\section{Supporting Information}

\section{Measurements}

MALDI-TOF mass spectra were taken on a Voyager DE Pro instrument. $\alpha$-Cyano-4-hydroxy cinnamic acid $[10 \mathrm{mg} / \mathrm{mL}$ in acetonitrile/water $(1: 1, \mathrm{v} / \mathrm{v})]$, sinnapic acid $(10 \mathrm{mg} / \mathrm{mL})$ and 3-hydroxy-2-picolinic acid $(80 \mathrm{mg} / \mathrm{mL})$ were used as matrices for PNAs, proteins, and RNAs, respectively. Products of the S1 nuclease digestion of aminoacylated tRNAs was monitored by analytical reverse phase HPLC (Waters, $\mu$ Bondasphere, $5 \mu \mathrm{C} 18100 \AA$, 3.9x150, flow rate $0.6 \mathrm{~mL} / \mathrm{min}$ with gradient $0-100 \%$ methanol in $0.1 \mathrm{M}$ ammonium acetate $(\mathrm{pH} 4.5)$ over $50 \mathrm{~min}$ ) by using a fluorescence detector $\left(\lambda_{\mathrm{ex}}=285 \mathrm{~nm}, \lambda_{\mathrm{em}}=335 \mathrm{~nm}\right)$. The observed mass values were compared with the exact mass when isotropic peaks were detected separately, or otherwise with the average mass.

\section{Synthesis of a 9-mer peptide nucleic acid carrying a 2-naphthylalanyl thioester that is linked to the $\mathrm{N}$-terminal through a spacer chain (H-2napAla-S-sp-PNA)}

PNA monomers were purchased from Applied biosystems. PNA of $N$-TGGTGCGAA-Lys(Boc)-Lys(Boc)- $\mathrm{NH}_{2}-\mathrm{C}$ sequence was synthesized by solid-phase method with an Fmoc $N$-protecting group as reported by Christensen $e t$ $a l .{ }^{1}$ Fmoc-SAL-PEG-Resin (Watanabe chemicals, Hiroshima, Japan) was used as a supporting resin. The peptide on the resin was further extended by two Gly units and by Fmoc- $p$-aminobenzoic acid (Watanabe Chemicals, Hiroshima, Japan). The amino acid thioester was introduced to the resin-bound peptide by the following procedure.

To the $N$-deprotected peptide, 5 eq of dithiodiglycolic acid, 5 eq of $N, N, N^{\prime}, N^{\prime}$-tetramethyl- $O$-(7-azabenzo-triazol-1-yl)uronium hexafluoro- phosphate (HATU), and 10 eq of diisopropylethylamine (DIEA) were added to the resin in $N, N$-dimetylacetamide (DMAA). After $3 \mathrm{~h}$, the resin was washed and the disulfide unit was reduced by dithiothreitol (DTT) for $4 \mathrm{~h}^{2}$ The thioglycolic acid unit 
formed was reacted with 5 eq of $N$-pentenoyl-L-2-naphthylalanine (Pen-2napAla) or $N$-Boc derivative in the presence of 5 eq of diethyl phosphorocyanidate (DEPC), and 10 eq of DIEA in DMAA for 1 day. Finally, the PNA was cleaved off from the resin by treating with TFA for 15 min. By this procedure, the Boc protecting group of 2napAla, Lys and the $N$-benzhydyloxycarbonyl (Bhoc) protecting group on the nucleobases were also removed. The peptide was purified on reverse phase HPLC (flow rate $1 \mathrm{~mL} / \mathrm{min}$ with gradient $0-50 \%$ acetonitrile in $0.1 \%$ TFA over $50 \mathrm{~min}$. The purified peptide was lyophilized and dissolved in anhydrous DMSO to make $0.5-1 \mathrm{mM}$ solution. The DMSO solution was stable for several months at $-20^{\circ} \mathrm{C}$. Concentration of the peptide was determined by the absorbance at $260 \mathrm{~nm}$ with an absorption coefficient of $83600 \mathrm{M}^{-1} \mathrm{~cm}^{-1}$ that includes contribution of 2napAla unit. ${ }^{3}$ H-2napAla-S-sp-PNA: MALDI-TOF MS $(\mathrm{m} / \mathrm{z})$, exact mass for $(\mathrm{M}+\mathrm{H})^{+}$, 3276.33; obsd, 3275.80. (Figure S1).

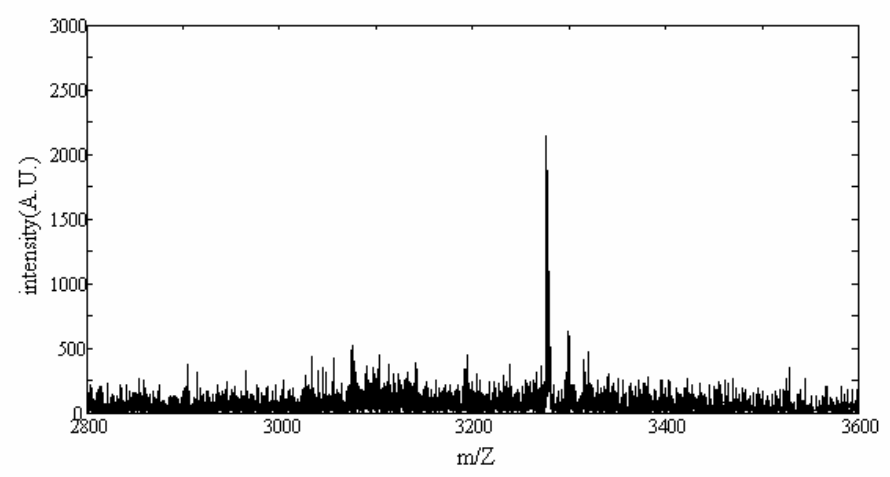

Figure. S1. MALDI-TOF MS spectrum of H-2napAla-S-sp-PNA.

By a similar procedure, peptides with L-1-naphthylalanine (1napAla) was synthesized. H-1napAla-S-sp-PNA: MALDI-TOF MS (m/z), average mass for $(\mathrm{M}+\mathrm{H})^{+}, 3278.12$; obsd: 3278.12 .

In the case of pentenoyl protecting group, the cleaved product Pen-2napAlaS-sp-PNA, was purified by reverse phase HPLC, lyophilized and dissolved in anhydrous DMSO. Pen-2napAla-S-sp-PNA: MALDI-TOF MS (m/z); average mass for $(\mathrm{M}+\mathrm{H})^{+}:$3358.37; obsd: 3358 (Figure S2).

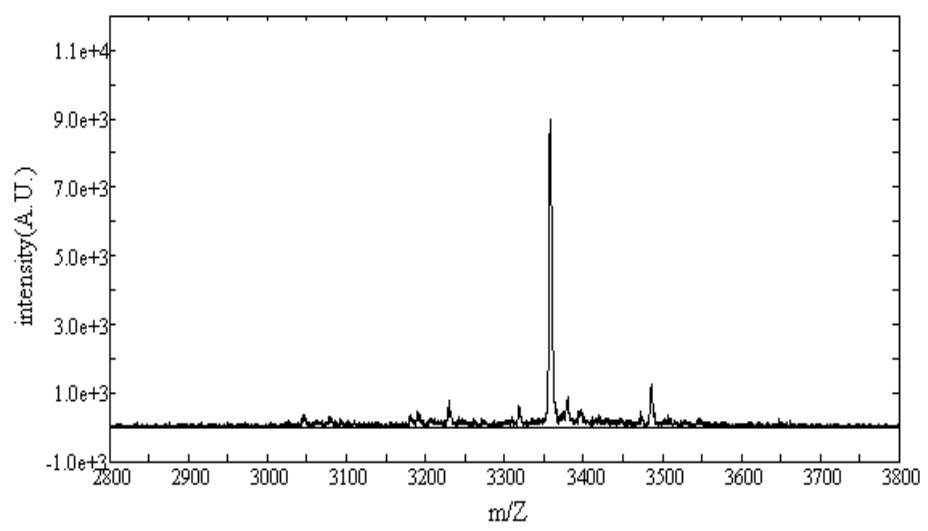

Figure. S2. MALDI-TOF MS spectrum of Pen-2napAla-S-sp-PNA. 
Peptides with L-2-anthrylalanine (2antAla) were also synthesized. L-2-Anthrylalanine was purchased from Watanabe Chemicals (Hiroshima, Japan). Pen-2antAla-S-sp-PNA: average mass for $(\mathrm{M}+\mathrm{H})^{+}, 3410.28$; obsd, 3410.42.

\section{Deprotection of pentenoyl group}

The pentenoyl group was removed by iodine treatment on the resin. ${ }^{5}$ The resin was immersed in DMAA $(600 \mu \mathrm{L})$ and $10 \mu \mathrm{L}$ of iodine $(100 \mathrm{mM})$ in $\mathrm{H}_{2} \mathrm{O} / \mathrm{THF}$ (1/1) mixture was added. The mixture was stand for $10 \mathrm{~min}$ at room temperature. The resin was washed with DMF for three times and then the peptide was cleaved off with TFA.

The iodine treatment of Pen-2antAla-S-sp-PNA gave an oxidized product of anthryl group that does not fluoresce. Therefore, a Boc-2antAla was used in this case. The Boc group was removed under the cleavage condition. H-2antAla-S-sp-PNA: MALDI-TOF MS $(\mathrm{m} / \mathrm{z})$, average mass for $(\mathrm{M}+\mathrm{H})^{+}$, 3328.34; obsd, 3328.59.

Melting curves for hybrids of PNAs of different chain lengths with oligo RNA UV melting curves were measured for hybrids of PNAs of $C$-AAGCGTGGT- $N$ (9-mer), $C$-AGCGTGGT- $N$ (8-mer), $C$-GCGTGGT- $N$ (7-mer), and $C$-CGTGGT- $N$ (6-mer) with a 11-mer oligo RNA (3'-AAUUCGCACCA-5'). Melting temperatures were determined from the temperatures that give the steepest slope of the melting curves. A typical example is given for the 9-mer PNA as shown in Figure S3. The melting temperatures were: $73^{\circ} \mathrm{C}$ for the 9 -mer, $70^{\circ} \mathrm{C}$ for the 8 -mer, $61^{\circ} \mathrm{C}$ for the 7 -mer and $52^{\circ} \mathrm{C}$ for the 6 -mer.

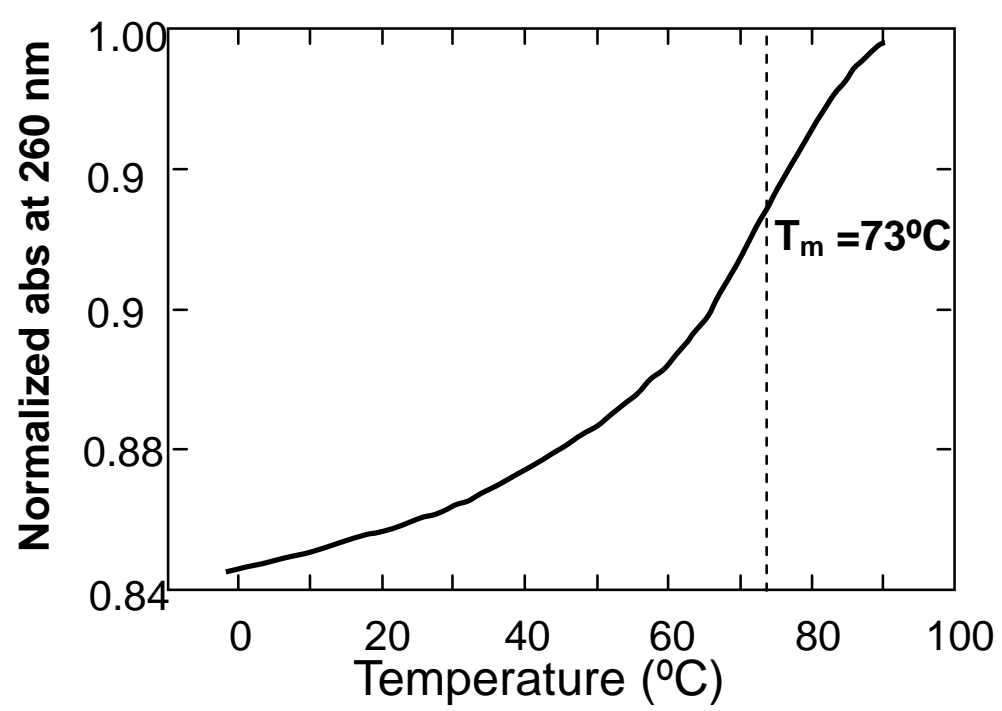

Figure S3. UV melting curve for a hybrid of 9-mer PNA with a 11-mer oligo RNA. $[\mathrm{PNA}]=5 \mu \mathrm{M},[\mathrm{RNA}]=5 \mu \mathrm{M}, 100 \mathrm{mM}$ phosphate buffer at $\mathrm{pH}$ 7.0. 


\section{Melting curves of the hybrids of FAM-sp-PNA with yeast phenylalanine tRNA $\mathbf{C C C G}_{\text {CC }}$}

The melting temperature was measured for the hybrids of the PNA and tRNA. To this end, 4(5)-carboxyfluorescein (FAM) was attached to the sp-PNA on the resin with HATU/DIEA. The FAM-labeled PNA was cleaved off from the resin with TFA and purified on HPLC. A FAM-labeled PNA of $N$-TGGTGC-C sequence (6-mer) was also synthesized.

FAM-sp-PNA: MALDI-TOF MS (m/z), average mass for $(\mathrm{M}+\mathrm{H})^{+}, 3365.1$; obsd, 3367. FAM-sp-PNA (6-mer): MALDI-TOF MS (m/z), exact mass for $(\mathrm{M}+\mathrm{H})^{+}$, 2521.98; obsd, 2521.37.

The FAM-labeled PNAs were mixed with an equimolar concentration of yeast phenylalanine tRNA. Fluorescence polarization was measured on a BEACON instrument as a function of temperature at an interval of $5^{\circ} \mathrm{C}\left(\lambda_{\mathrm{ex}}=494 \mathrm{~nm}\right.$, $\lambda_{\mathrm{em}}=517 \mathrm{~nm}$ ). The concentration of the FAM-labeled PNA was $0.1 \mathrm{mM}$ in $100 \mathrm{mM}$ phosphate buffer, $\mathrm{pH} 7.5$.

The fluorescence polarization varies with temperature by itself. Therefore, the hybridization ratio was calculated from the polarization values for the free FAM-labeled PNA $\mathrm{P}_{\mathrm{f}}, 1: 1$ mixture of the FAM-labeled PNA and the tRNA $\mathrm{P}_{\mathrm{o}}$, and for the fully bound PNA in the presence of 10-fold amount of the tRNA $\mathrm{P}_{b}$, respectively, at each temperature using the following equation.

Hybridization ratio $=\left(\mathrm{P}_{\mathrm{o}}-\mathrm{P}_{\mathrm{f}}\right) /\left(\mathrm{P}_{\mathrm{b}}-\mathrm{P}_{\mathrm{f}}\right)$

Results are shown in Figure S4.

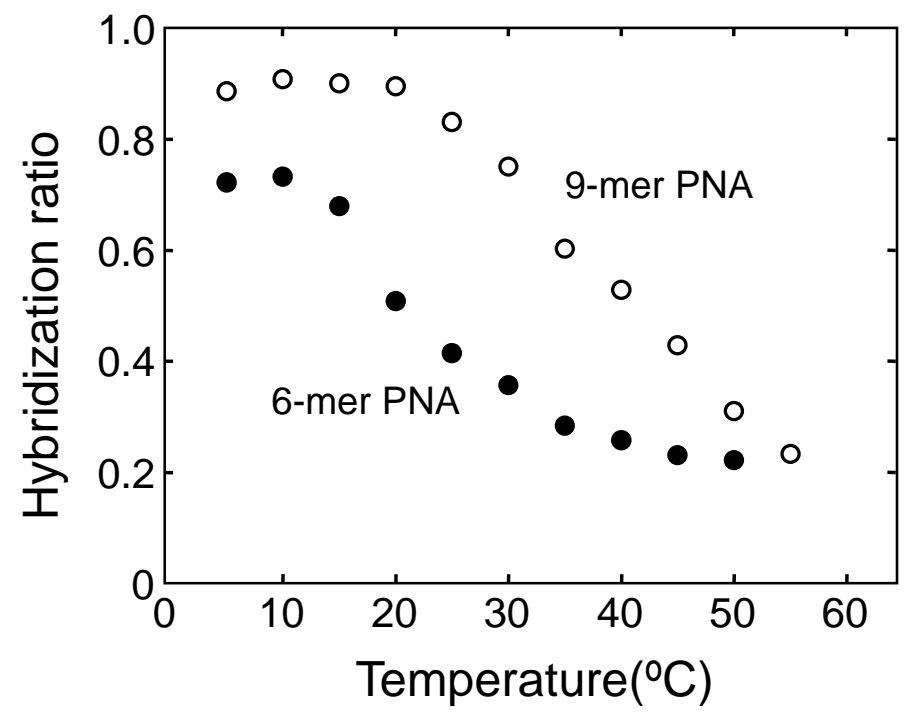

Figure S4. Melting curves for the 1:1 mixtures of FAM-labeled PNA with tRNA. Concentration of each component $=0.1 \mathrm{mM}, \mathrm{pH} 7.5100 \mathrm{mM}$ phosphate buffer. 
The $\mathrm{T}_{\mathrm{m}}$ values were estimated to be about $25^{\circ} \mathrm{C}$ for the 6-mer PNA and about $38^{\circ} \mathrm{C}$ for the 9-mer PNA.

Procedure of the aminoacylation of yeast tRNA with H-aa*-S-sp-PNA or with Pen-aa*-S-sp-PNA and the denaturing PAGE analysis of the aminoacylation products

The optimum conditions for the aminoacylation is as follows. A mixture (total volume $10 \mu \mathrm{L}$ ) that contained $50 \mu \mathrm{M} \mathrm{H}$-aa*-S-sp-PNA or Pen-aa*-S-sp-PNA, 50 $\mu \mathrm{M}$ of tRNA and $50 \mu \mathrm{M}$ of dithiothreitol in $300 \mathrm{mM}$ phosphate buffer at pH7.5. was prepared and kept at $37^{\circ} \mathrm{C}$ for $30 \mathrm{~min}$ for $\mathrm{H}$-aa*-S-sp-PNA and $1 \mathrm{~h}$ for Pen-aa*-S-sp-PNA. The mixture was then acidified by adding $50 \mu \mathrm{L}$ of $1.5 \mathrm{M}$ potassium acetate $(\mathrm{pH} 4.5)$ and washed with acidic phenol and then with chloroform. The aqueous layer was poured into $360 \mu \mathrm{L}$ of ethanol to precipitate the tRNA at $-30^{\circ} \mathrm{C}$. After storing at $-30^{\circ} \mathrm{C}$ for $1 \mathrm{~h}$, the ethanol suspension was centrifuged at $15000 \mathrm{rpm}$ for $30 \mathrm{~min}$ at $4^{\circ} \mathrm{C}$ and the supernatant was removed. The precipitate was dried under vacuum and, if necessary, stored at $-80^{\circ} \mathrm{C}$. During the above procedure, the PNA was removed as an ethanol soluble component. The yield of aminoacylation was determined by gel-shift assay using a $20 \times 20 \mathrm{~cm}$ denaturing $12 \%$ PAGE ( $7 \mathrm{M}$ urea/0.1 M sodium acetate, $\mathrm{pH} 4.6$ ) under 200 Volt at $4^{\circ} \mathrm{C}$. After the electrophoresis, the gel was rinsed with water for $5 \mathrm{~min}$ and shaken for $10 \mathrm{~min}$ in $10^{-5} \mathrm{M}$ ethidium bromide solution in $0.1 \mathrm{M}$ sodium acetate. The gel was rinsed with water. The tRNA component was visualized on UV irradiator. The digital image was analyzed on an Image Quant v.5.2 (Molecular Dynamics) software.

\section{Synthesis and characterization of the authentic samples of the aminoacylation product}

Authentic sample of AMP-2napAla was synthesized by nuclease S1 treatment of chemically synthesized pdCpA-2napAla, ${ }^{4}$ followed by HPLC purification. MALDI TOF-MS. (m/z) obsd: 545.55; exact mass calcd for AMP-2napAla $(\mathrm{M}+\mathrm{H})^{+}:$545.16. (Figure S5).

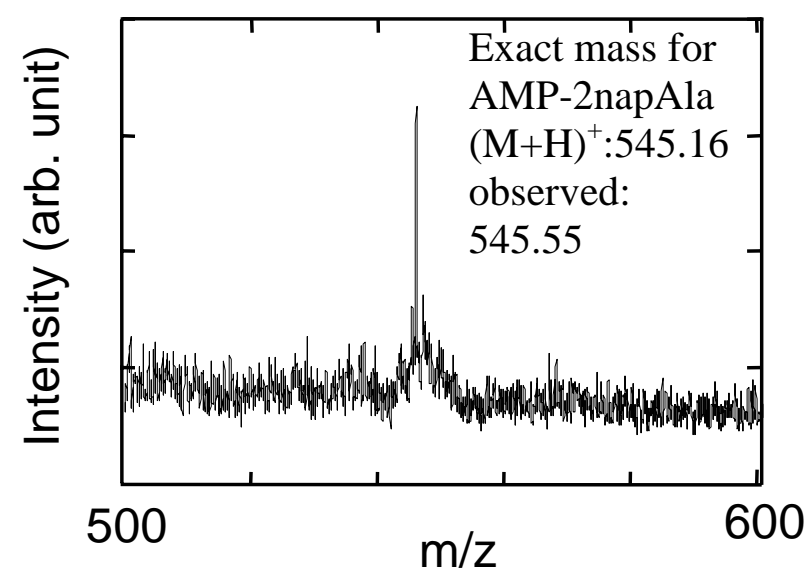


Figure S5. MALDI-TOF MS spectrum of AMP-2napAla prepared by an S1 decomposition of pdCpA-2napAla. ${ }^{4}$

Similarly, AMP-(Pen-2napAla) was obtained. MALDI TOF-MS. (m/z) obsd: 625.57; exact mass calcd for AMP-(Pen-2napAla) $(\mathrm{M}+\mathrm{H})^{+}$: 626.19. (Figure S6).

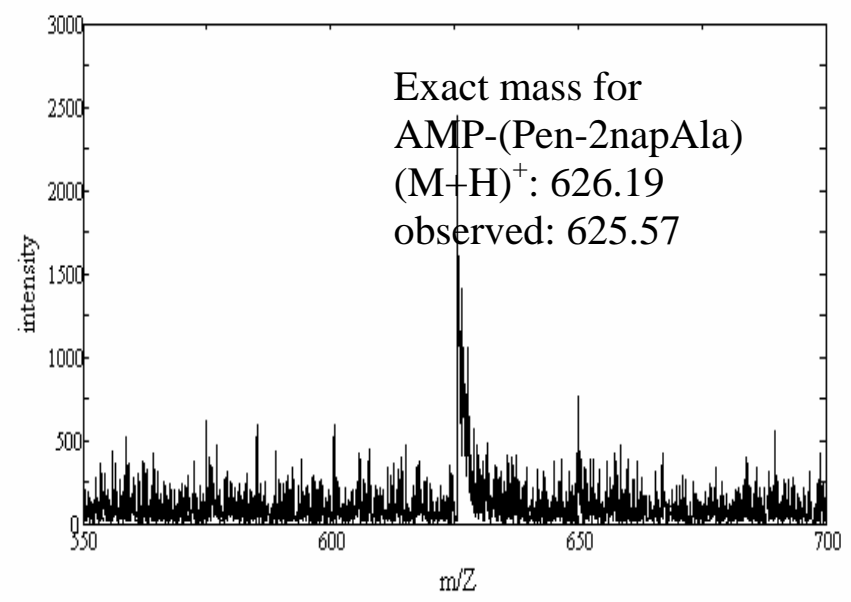

Figure S6. MALDI-TOF MS spectrum of AMP-(Pen-2napAla).

\section{Nuclease S1 digestion of the aminoacylation product}

The dry sample of aminoacylated tRNA was dissolved in $20 \mu \mathrm{L}$ of an enzyme mixture that contained $17.5 \mu \mathrm{L}$ of pure water, $2 \mu \mathrm{L}$ of $10 \mathrm{xS} 1$ buffer and $0.5 \mu \mathrm{L}$ of nuclease S1 (Takara, Japan). The mixture was incubated at $37^{\circ} \mathrm{C}$ for $15 \mathrm{~min}$ and mixed with $20 \mu \mathrm{L}$ of $0.1 \%$ aqueous trifluoroacetic acid/acetonitrile (1/1) mixture. HPLC analysis of the digested products showed fluorescent peaks at the same retention times (around $15 \mathrm{~min}$ ) as the authentic AMP-2napAla (Figure 2 in the text). The latter peaks were collected and analyzed on MALDI TOF-MS (m/z): obsd: 544.95; exact mass calcd for AMP-2napAla $(\mathrm{M}+\mathrm{H})^{+}$: 545.16. (Figure S7).

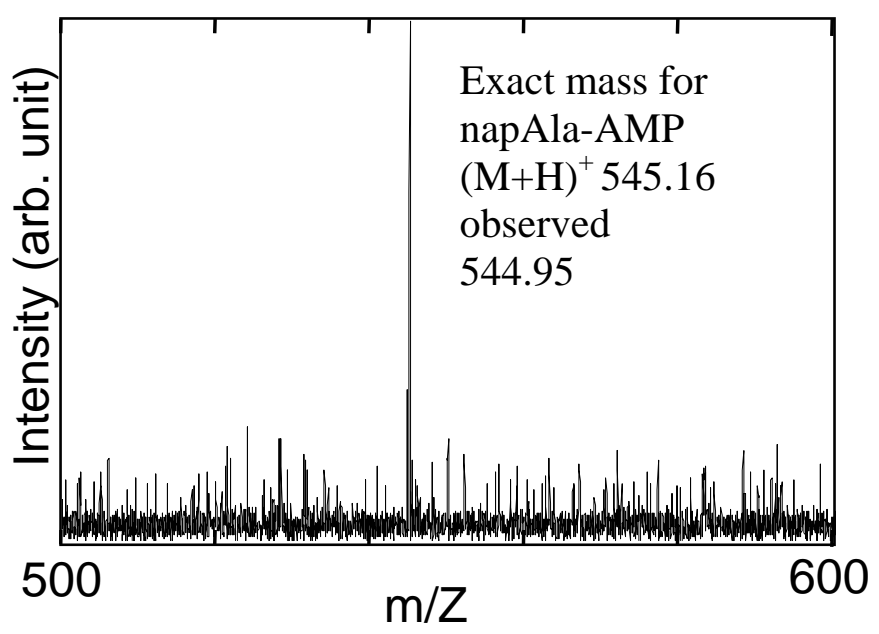


Figure S7. MALDI-TOF MS spectrum of the aminoacylation product of tRNA after nuclease treatment. The HPLC peaks around 15 min were collected.

\section{Orthogonality of yeast phenylalanine tRNAs in the E.coli S30 in vitro protein synthesizing system}

For the in situ aminoacylation to be successful, the target tRNA must not be aminoacylated by any ARSs existing in the system but, once it was aminoacylated, it must work as an aminoacyl tRNA as other ones. Unfortunately, yeast phenylalanine RRNA $_{\mathrm{CCCG}}$ did not satisfy this orthogonal condition as shown in Figure S8, lane (1). In this system, free yeast phenylalanine tRNA $\mathrm{CCCG}_{\text {was }}$ added into an E.coli S30 system together with a mRNA for streptavidin including a ${ }^{83}$ CGGG 4-base codon. Full length protein was synthesized in $8 \%$ yield with respect to the yield of the wild-type streptavidin, indicating aminoacylation of the

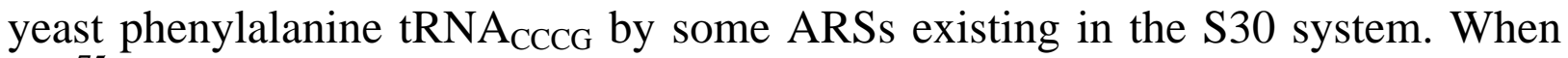
the ${ }^{75} \mathrm{C}$ was replaced by $\mathrm{dC}$, the protein yield became much smaller. We employed this orthogonalized tRNA for the in vitro synthesis of mutant streptavidin. The $\operatorname{tRNA}\left({ }^{75} \mathrm{dC}\right)$ was synthesized by the Hecht method.

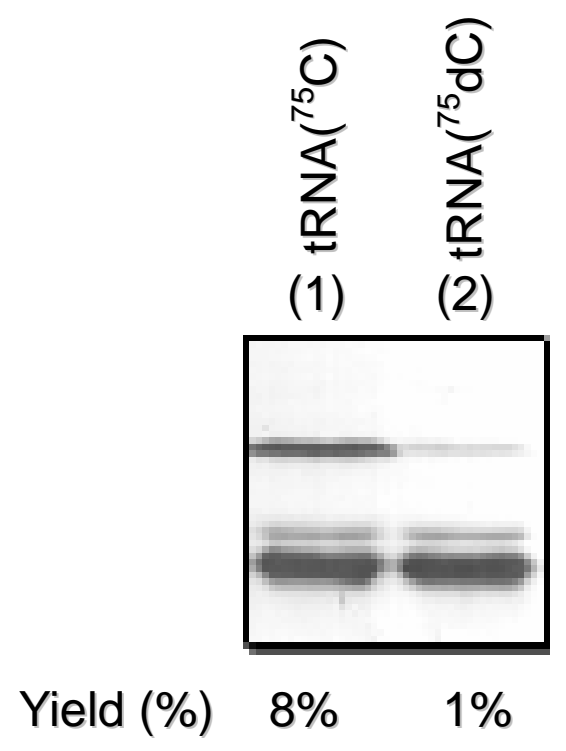

Figure S8. Western blotting of the translation products of E.coli S30 in vitro system with ${ }^{83} \mathrm{CGGG}$ streptavidin mRNA. Lane (1): free yeast phenylalanine tRNA with CCCG anticodon $(20 \mu \mathrm{M})$ was added, Lane (2): free tRNA $\left({ }^{75} \mathrm{dC}\right)(20$ $\mu \mathrm{M})$ was added. The yield of full-length protein was taken to be $100 \%$ for wild-type streptavidin.

Base sequence of yeast phenylalanine tRNA with a CCCG 4-base anticodon 


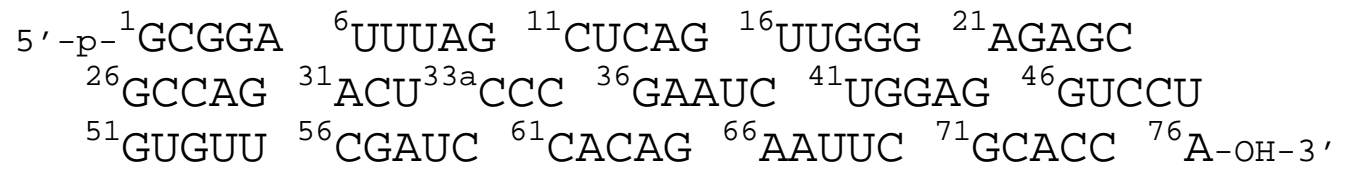

\section{References}

(1) Christensen, L.; Fitzpatrick, R.; Gildea, B.; Petersen, K.; Hansen, H.; Koch, T.; Egholm, M.; Buchardt, O.; Nielsen, P.; Coull, J.; Berg, R. J. Pept. Sci. 1995, 1,175 .

(2) Liu, X.; Balasubramanian, S. Tetrahedron Lett. 2000, 41, 6153.

(3) PerSeptive Biosystems, Inc. User's Guide Part Number 601308. 1998 Rev.2.

(4) Hohsaka, T.; Kajihara, D.; Ashizuka, Y.; Murakami, H.; Sisido, M. J. Am. Chem. Soc. 1999, 121, 34.

(5) Madsen, R.; Roberts, C.; Fraser-Reid, B. J.Org.Chem.,1995, 60, 7920. 